\title{
Decentralisation is Coming: The Future of Blockchain
}

\author{
Mark Fenwick ${ }^{1}$, Erik P.M. Vermeulen ${ }^{2}$ \\ ${ }^{1}$ Kyushu University \\ 2 Tilburg University
}

Correspondence: E.P.M.Vermeulen@uvt.nl

Received: 31 July 2019 Accepted: 12 August 2019 Published: 16 August 2019

\begin{abstract}
Advocates of blockchain believe that distributed ledger technologies can provide us with a technological infrastructure to challenge the concentrated power of tech giants such as Amazon, Facebook and Google, and create a more equitable, sustainable and decentralized world. This paper considers these claims and concludes that they are preferable to defending the status quo or arguing that a solution might be found in more and better regulations. Nevertheless, the future remains highly uncertain and we are currently living in a rapidly evolving "space" between two competing realities: a centralized old-world reality and a fast-emerging, but, as yet, incomplete, decentralized reality. We remain optimistic that decentralization is coming but identify powerful competing forces seeking to preserve the status quo. As such, we must encourage more organizations - business, government, investors, charities - to experiment with distributed ledger technologies and to participate actively in the digital transformation. We need more experimentation to address the current shortcomings of decentralisation and to ensure the early arrival of mainstream applications of a technology that has the potential to solve some of the most pressing global challenges of a digital age.
\end{abstract}

Keywords: Bitcoin, Blockchain, Crypto-Economy, Decentralization, Digital Transformation, Distributed Ledgers, Disintermediation, Ethereum, Satoshi Nakamoto, Smart Contracts, Technology

JEL Classifications: K20, K22, K24, L50, M21, O30, O31, O33, O35, Q 55

\section{Introduction}

Advocates of blockchain - let's call them the "Evangelists" believe that decentralised ledger technologies have the potential to address many of the most pressing problems of the digital age. We are all familiar with the problems. The massive concentration of economic power in companies such as Amazon, Apple, Facebook, Google, etc. The large-scale abuse of privacy via the hoarding and selling of personal information online. The systematic (and state-sponsored) political misinformation operations and the calculated spreading of socalled "fake news."

The Evangelists believe that these and other problems can only be solved with more technology, rather than through more rules and regulations. And, in the strongest version of this story, Evangelists claim that blockchain technologies have the potential to transform capitalism and herald in a more sustainable, egalitarian, and decentralised world. In this piece, we would like to offer a defense of this Evangelist view. Not least because it offers a more compelling vision of the future than those in denial about the scale of the challenges created by the digital revolution or those arguing that more and better rules and regulations are the answer.

Nevertheless, it is easy to be skeptical or cynical in the face of such idealism. After all, the Evangelist narrative cuts against previous experience of disruptive technologies. ${ }^{i}$ Historians have often noted that new technologies start in the hands of nerds and dreamers motivated by the desire to make the world a better place (the Apple of Steve Wozniak). But this rarely lasts, and successful technologies ultimately end up in the hands of powerful corporations driven the desire to maximize profits and shareholder value (the Apple of Steve Jobs). According to this view, the Internet story is just the latest chapter in a sorry tale of a human failure to ensure that technology works for the benefit of all. After all, the corporate giants of today are amongst the biggest companies that have ever existed and there is ever-increasing inequality in wealth distribution. ${ }^{\text {ii }}$ Everything we know about the history of technology and capitalism should make us treat the Evangelist position with caution. 
Moreover, the transformative potential of distributed ledgers can sometimes be difficult to see through all the noise and hyperbole that surrounds the "Blockchain Revolution." unfortunate, for instance, that blockchain technologies have attracted greedy opportunists and fraudsters keen to make a quick profit. The result? A series of ICO scams and other scandals that discredited the technology in many people's eyes before it had any real-world impact on our everyday lives. But, once the blockchain hype fades, and the opportunists have moved on to the next "big thing," will these technologies be able to deliver on their potential and promise? Or, are the skeptics and nay-sayers right when they suggest that this is just hype "all the way down?"

The paper has three parts. In the next section ('The Rise of Centralized Platforms'), we describe the emergence of the new tech giants that leveraged the new possibilities of the Internet to develop a platform business model. Furthermore, we identify various pressures that create ever-more centralization and concentrations of economic power in the platform economy. The next section ('The Decentralized Alternative of Blockchain Evangelists') identifies the Evangelical alternative; a radically different account of the future that seeks to utilize distributed ledger technologies to realize the idealistic vision of the original architects of the Internet as a decentralized global communications network. In doing so, a genuine alternative to the current tech giants can be conceived. We conclude ('Experiments in Decentralization') with some brief reflections on the need for more participation in the development of blockchain technology, smart contracts, and cryptocurrencies to address the current shortcomings of decentralization and to ensure that we will soon see mainstream applications of the technology.

The takeaway? We are currently living in a fast-developing "space" between two competing realities: a centralized "old world" reality and a fast-emerging, but, as yet, incomplete, "decentralized reality." We are cautiously optimistic that decentralization is coming, but acutely aware of the competing forces that seek to preserve the status quo.

\section{The Rise of Centralised Platforms}

The Internet today comprises two connected, but distinct, layers. Firstly, there are a series of open source protocols, such as HTTP, GPS, IMAP, POP, SMPT, etc., that first allowed computers to communicate with one another across global networks and which still provide the basic infrastructure of the system. The key characteristic of such protocols is that no one owns them, and anyone can use them free of charge. There is no license fee involved in using HTTP to set up a web page, or in using SMTP to send an email, or GPS to identify location. Secondly, there is the web-based layer, which emerged later, and which sits on top of the protocols providing various services. Think Amazon, Facebook, Google, Twitter: this layer is operated by profit-seeking corporations that - in contrast to the authors of the protocols - have always sought to maintain tight control over their services and operations. The history of the Internet can be told as a story of a shift in power from the open protocol idealism of the early years to the closed, centralized and controversial capitalism that dominates today.iv

Many of the companies operating on this second layer provide what me might call a coordination function between two or more groups of users, and this business model is usually described as a "platform." Some platforms facilitate connections between the buyer and seller of goods (eBay, Amazon, Alibaba); some facilitate connections between those wanting a service and those willing to provide it (Uber, Airbnb); and others simply facilitate connections (information exchange) between friends (Facebook), content creators and consumers (You Tube, Medium, Netflix) or app developers and users (Google, Apple). However, what is common to all platforms is that they coordinate connections between "creators" and "extractors" of value and the platform generates a profit from making these connections, either by taking a commission or advertising.

The emergence and growth of platforms is a significant economic and cultural event, not least because they have become a routinized feature of everyday life within a short period. To illustrate this rise, consider that it took the radio 38 years to reach 50 million users. It took television 13 years to achieve the same degree of market penetration. But Facebook "only" needed two years to gain the same number of users. Now, it has an active user base of over 2 billion.

Moreover, the global proliferation of digital technologies and communication networks means that platforms can be established anywhere. The emergence of hugely successful platforms in China (Alibaba) or Indonesia (Go-Jek) illustrate the universal appeal and adaptability of this business model. It also shows how less developed economies might employ platforms as a means of "leapfrogging" an earlier (industrial) phase of economic development and "jump" directly into the digital age.vi Go-Jek "only" needed three years to go from 100,000 
orders a day (in 2015) to $100+$ million orders across $18+$ services in 2018. vii

What is clear, however, is that as platforms have scaled, they have struggled to maintain their initial promise and platforms that were once disruptive have lost much of their initial appeal. And it is hard to ignore the problems experienced and created by platforms. There are too many recent examples of wellknown platforms "forgetting" the importance of improving people's lives. Although there are a number of reasons why platforms have tended to become more centralized and more "corporate," and have experienced these kinds of difficulties, two factors are worth emphasizing:

Firstly, markets tend to prefer a single service provider. Take Airbnb as an example. When a new platform service like Airbnb starts to take off, there's a strong incentive for the market to consolidate around that single provider. The fact that more customers start to use the Airbnb app means that more roomproviders are attracted to join the platform, which in turn attracts more people looking for a room, as there are now more choices of rooms. As such, platforms are acutely sensitive to network effects. ${ }^{\text {vii }}$ The more users there are on one platform, the more everyone benefits (more and better choices, more ratings, etc.). In addition, individuals who already have the app installed and their details stored on Airbnb have a strong incentive to stay with that platform. The costs of migrating to a different provider become prohibitive, even if the company or individuals running the company are revealed to be engaged in dubious practices. Although many consumers may very well prefer multiple service providers, there are clear incentivizes pushing everyone to stick with one dominant player, once that dominant platform has emerged.

Second, the need to innovate continually, whilst at the same managing the legal risk created by rapid expansion, requires more centralized forms of organization and governance. Platforms often start with a simple, idealistic proposition ("let's bring people together"). But, over time, they add more and more features, making their technological infrastructure more complex. ${ }^{\text {ix }}$ The downside of this is that more developers are then needed to accurately deal with the increased technology complexity and managing such complexity requires more centralized and hierarchical organizational forms with more elaborate control mechanisms. This is particularly true of companies that scale globally. And when platforms become more prominent, they need to attract more investors and investment to fund further innovation. Again, this transforms the incentives of platform owners and short-term performance becomes critical. To improve financial performance or save costs, platforms may feel the need to change the rules of the game from one day to the other (without consulting the users of the platform) and the belief that such agility is better achieved with hierarchical and centralized governance structures can easily gain ascendancy.

We might say that platforms have exhibited a tendency towards two different types of centralization. On the one hand, "cartelization," in which fewer and fewer players dominate the market for a particular service, and, on the other hand, "corporatization," in which there is an ever-greater internal concentration of authority based on a clear and closed hierarchy.

If we accept this story of the inevitable decline of platforms, how should we respond? Again, there are competing views. Some claim that our only hope is to use the power of the Leviathan (the state or regional organizations, such as the EU) to rein in these corporate giants, through more and better rules and regulation. ${ }^{\mathrm{x}}$ Think anti-trust laws, data protection laws or laws controlling online speech. According to this line of thinking, we can't fix the problems with more technology. Recently, we can hear more and more talk around this "topdown," regulatory solution.

\section{The Decentralised Alternative of the Blockchain Evangelists}

The Evangelists, however, take a different view. These are not problems that can easily be solved by more or even smarter regulation, as the power and reach of the Internet giants is just too great for any regulation to be meaningful or effective. The size of many platforms makes them largely immune to state action. ${ }^{x i}$ Instead, the Evangelists recognize the importance of technology-based solutions that can provide us with the vision and direction to build something better. This is a view that needs to be taken seriously and it is in this context that we need to think about distributed ledger technologies, such as blockchain, and smart contracts. ${ }^{x i i}$

The key claim of Evangelists is that things can be different and that distributed ledger technologies have the potential to bring about a transformation to a better world. xiii To understand why and how, it is helpful to briefly go back to the origins of blockchain and the original white paper by Satoshi Nakamoto. ${ }^{\text {xiv }}$ In this first statement, Nakamoto proposed a system for a 
digital currency that did not require a centralized trusted authority to verify transactions. Two key elements characterize the general system that was proposed in the Bitcoin whitepaper:

Firstly, a database scattered across many computers, with no single authority controlling and verifying the authenticity of the data. Secondly, the "work" of maintaining the database - what we now refer to as "mining" - was rewarded with small payments, in the form of tokens. If you used a part of your computer's power to maintain the integrity and security of the database, you would receive a reward in the form of tokens that could then be used to "buy" services or sold to third parties for profit. These tokens would grow increasingly difficult to earn over time, ensuring a certain amount of scarcity in the system. If you helped in the beginning (and helped the database to develop and grow) you would receive a larger reward, thus incentivizing early stage participation.

Evangelists believe that this combination of ideas are revolutionary.xv Firstly, they provide a way of agreeing on the contents of a database without anyone being in charge of, owning or otherwise controlling that database. Secondly, they provide a mechanism for rewarding people that made the database more valuable, but - crucially - without those people being paid by an owner of the database or owning shares in the corporation that controls the database. There would be no owner or controlling corporation of such decentralized databases. Nakamoto provided a model for supporting open protocols that wasn't available when the first tech giants emerged. And, for this reason, they have the potential to challenge the tech giants and change the world.

But, how does this technology have potential to transform capitalism and how is it connected to the protocol layer of the Internet described above? A comparison with Airbnb can be used to illustrate the possibilities of a distributed ledger model. A new open protocol could be created that contains a request: "I would like a room in PLACE between DATES." A decentralized blockchain database might then record the metadata of all users, such as personal information, past trips, credit card details, preferences and user and host rankings. The protocol for transmitting this request out onto the Internet would be completely open. Anyone (individuals, private companies, public authorities) who wanted to develop an app for responding to such requests would then be free to do so. In this model, when you transmit your request, you would not need to commit ex ante to a single provider (as you do now with Airbnb), but you would instead be free to announce your wishes to the world via the secure protocol and wait for competing offers from diverse providers of accommodation, ranging from anyone with a spare room though to large multinational hotel companies.

Tokens would be vital in allowing such a protocol to develop and scale, and early adopters would be rewarded with tokens that they could then use to either buy accommodation services themselves or sell on an exchange for real world currencies. Moreover, early adopters (app developers, providers of accommodation, etc.) would receive a proportionately larger share of tokens for entering and helping to develop the new ecosystem. As the protocol developed it would then attract outside investors, which would give the token a greater monetary value that, in turn, would encourage more participation.

Critics might argue that one company or group of companies might monopolize the new protocol, in the same way that the tech giants of today dominate various sectors of the Internet economy. Indeed, fully-fledged decentralized blockchain networks do not exist yet. Consider the technical and operational shortcomings of the Bitcoin blockchain. In discussions with mathematicians and other technologists, the following weaknesses are usually highlighted. Bitcoin's proof of work protocol has led to "mining pools" because of economies of scale and unbalanced reward structures. The anonymity in the blockchain network means that it is prone to "Sybil attacks" and " $51 \%$ attacks."

Still, there are advantages in an open source plus decentralized database model that makes such a process of "cartelization" much less likely. For a start, it wouldn't present the same opportunities for abuse and manipulation that you find in the closed, centralized systems of Amazon, Facebook, etc. If a particular service provider did something I didn't like, it would be much easier to switch to an alternative service provider, as my information would not be retained by the service provider on a centralized database, but a decentralized, open source database connected to the protocol. The open standard would have a discipling effect on platform operators, as it would facilitate a level of migration (to other providers or simply opting out altogether) that is simply impossible today.

Tokens would also give a blockchain-based open protocol a number of advantages, in that it would provide an infrastructure to reward content creators. This seems preferable to the current situation on many platforms - especially social media platforms 
- where most content providers act without compensation, while the platform companies receive all the economic value of that content by selling advertising.

Finally, there are the potential security gains of a decentralized network. Would our personal information or transactions be more secure in a distributed blockchain than behind the elaborate firewalls of giant corporations like Google or Facebook? An openly readable ledger means anyone can check the integrity of transactions. The distributed cooperation component implies that "attackers" must be able to "outcompute" the entire network (which is practically impossible).

\section{Experiments in Decentralisation}

The takeaway from all of this? We are currently living in a fast developing "space" between two co-existing realities: a centralized "old world" reality and an emerging but incomplete new "decentralized reality." The centralized reality with its hierarchical organizations, rules, regulations, and institutions still prevails. It appears unlikely that we will soon say goodbye to our familiar, centralized procedures and organizations anytime soon.

Nevertheless, a more decentralized reality has already started to emerge. xvi As we have seen, trust in the "centralized companies" is already declining (mainly due to the concentration of power, wealth and information), and distributed ledger technologies, including blockchain, are viewed by many as offering a superior long-term model. These technologies have the potential to create real level playing fields, transparency and applications that run exactly as programmed without any possibility of downtime, censorship, fraud or third-party interference.

We have already passed the "tipping point" in our experimenting with decentralized technologies. ${ }^{\text {vvii }}$ There's simply no going back. So, instead of being locked into the traditional "centralized" world or remaining trapped in the space between the two realities, it is better to see how digital technologies are shaping the "new world" and affecting all of our relationships.

As such, it is necessary to become actively involved in the further development of blockchain and smart contracts and the creation of a decentralized reality. Only, if we build the new reality together, will we ensure that a decentralized world can reach its full potential and offer greater transparency, convenience, and trust. When we co-create the future together in this way, new jobs, opportunities, possibilities will inevitably emerge. And incorporating multiple perspectives - business, mathematics, and law - will be essential to make sure that we make the right decisions in our journey towards a better decentralized world.

The broader context for this project is a number of significant cultural shifts. Digital technologies have already changed our expectations. Consumers have become smarter, better connected, and more demanding. They love the "speed" and "convenience" offered by digital technologies and they are not willing to give it up. The consumers' "voice" has become more powerful than ever before. As a result, their relationship with business has changed dramatically. Even business-to-business companies need to take consumer views more seriously.

Who, when and where people "trust" has also changed. Whereas in the past, we relied heavily on institutions, intermediaries, and other third parties, we increasingly place our trust in digital systems and algorithms. It appears that we have less and less confidence in "old world" institutions. The speedy development of distributed ledger technology (including blockchain), smart contracts and artificial intelligence will only further automate trust. Institutionalized trust is replaced by "digital trust." It is obvious that the automation of "trust," "faith," and "confidence" has a tremendous impact on workeremployer relationships, the meaning of leadership, and how management operates. The opportunity to communicate and interact with peers directly (through social media and without the interference of third parties) makes us more entrepreneurial and creates new opportunities to be creative.

Our "new" relationship with digital technology also makes it possible to have peer-to-peer connections, communications, interactions, and transactions. Algorithms and data-analytics help us find partners, assistants, sponsors, help, accommodation, etc. Of course, these digital systems aren't flawless, but the fact is that we increasingly rely on more decentralised, peer-to-peer systems. The convenience of these new systems attracts us. The looser (digital) connections and interactions are so much faster and more comfortable than the old "formal" ways of making fixed appointments and ritualized meetings. The Millennial generation, in particular, appears to understand this. They view decentralization as a given for autonomy, responsibility, and happiness. Millennials - and this is a mindset, more than a generation - just seem more attuned to the freedoms and possibilities of a flatter world. They understand that hierarchical structures and an overreliance on 
formal procedures often discourage open and honest discussion, leading to either indifference, apathy or burnout.

"Fully-fledged" decentralization doesn't exist yet. But the decentralization trend is evident, and we must be better prepared. There is no time for procrastination, and we need to

\footnotetext{
i See, for example, Carlota Perez, Technological Revolutions \& Financial Capital (2002); Timothy Wu, The Master Switch: The Rise and Fall of Information Empires (2010).

ii See Scott Galloway, The Four: The Hidden DNA of Amazon, Apple, Facebook, and Google (2017).

iii Don Tapscott \& Scott Tapscott, Blockchain Revolution: How the Technology Behind Bitcoin is Changing Money, Business, and the World (2016).

ivWilliam Craig, 15 Biggest Internet Controversies of the Past Decade, FX Blog,
} (2018) available at: https://www.webfx.com/blog/web-design/15-biggestinternet-controversies-of-the-past-decade/.

v See Geoffrey G Parker, Marshall W. Van Alsyne \& Shandgeet Paul Choudry, Platform Revolution: How Networked Markets are Transforming the Economy and How to Make them Work for You (2016); Alex Moazed \& Nicholas J. Johnson, Modern Monopolies: What it Takes to Dominate the Twenty First Century Economy (2016).

vi The World Bank, for example, organized a Disrupting Development event on this theme in Bali in October 2018, available at: https://live.worldbank.org/disruptingdevelopment.

vii Erik P. M. Vermeulen, Three Ways to Grow Your Business in a Digital Age, Medium (2017) available at: https://hackernoon.com/3-ways-to-grow-yourbusiness-in-a-digital-age-86e8bb3f33d1.

viii See Paul Belleflamme \& Martin Peitz, Platforms and Network Effects, Handbook of Game Theory \& Industrial Organization 286-317 (2018); Nirmala Reddy, How to Harness the Power of Network Effects, Forbes (2018) available at: https://www.forbes.com/sites/forbescoachescouncil/2018/01/02/how-toharness-the-power-of-network-effects/\#2b41823462e8.

ix Platforms often use open source software and a "microservices" architecture to accelerate growth, be adaptable to change, and give more value to the end-users of the services. Think of these platforms as a collection of loosely coupled applications which are configured to interact through internal and external application programming interfaces (APIs). The API approach provides flexibility and windows to new and other platforms. It allows the platforms to attract innovative ideas from become smarter about decentralization in order to ensure that the Evangelist vision of the future comes to fruition. Of course, current technologies and developments aren't perfect (misuse of data, fake news, etc.). But these issues cannot be solved by traditional and centralized means (regulations, etc.). We must collaborate to find decentralized and tech-driven solutions now.

third-party developers. The downside is that more developers and more automation are needed to accurately deal with the increased technology complexity. This require more investments (more of which later) and a more centralized organization with more control and governance mechanisms.

x See, for example, Scott Galloway, The Four: The Hidden DNA of Amazon, Apple, Facebook, and Google (2017).

xi Mark Fenwick, Joseph A. McCahery, \& Erik P. M. Vermeulen, (2019). The End of 'Corporate' Governance: Hello 'Platform' Governance. European Business Organization Law Review, Vol. 20, No. 1, 171-199; Mark Fenwick \& Erik P. M. Vermeulen, A Sustainable Platform Economy \& the Future of Corporate Governance. European Corporate Governance Institute Law Working Paper, No. 441/2019, p. 1-38 (2019) available at: https://doi.org/10.2139/ssrn.3331508.

xii Mark Fenwick \& Erik P. M. Vermeulen, Time for Regulators to Open the 'Black Box' of Technology, Lex Research Topics in Corporate Law \& Economics Working Paper, No. 2019-2 (2019) available at: https://doi.org/10.2139/ssrn.3379205.

xiii Mark Fenwick \& Erik P. M. Vermeulen. A Primer on Blockchain, Smart Contracts \& Crypto-Assets, Lex Research Topics in Corporate Law \& Economics Working Paper, No. 2019-3, p. 1-20, (2019) available at: https://doi.org/10.2139/ssrn.3379443.

xiv Satoshi Nakamoto, Bitcoin: A Peer-to-Peer Electronic Cash System (2008), available at: https://bitcoin.org/bitcoin.pdf.

xv Steven Johnson, Beyond the Bitcoin Bubble, New York Times Magazine (January 16, 2018).

xvi See Mark Fenwick, Wulf Kaal, \& Erik P. M. Vermeulen, Why Blockchain Will Disrupt Corporate Organizations: What Can be Learned from the Digital Transformation, Journal of the British Blockechain Association, 1(2), 1-11, (2018) available at: https://doi.org/10.31585/jbba-1-2-(9)2018.

xvii See, for example, Mark Fenwick, Wulf A. Kaal, Erik P.M. Vermeulen, The Unmediated \& Tech-Driven Corporate Governance of Today's Winning Companies, University of St. Thomas (Minnesota) Legal Studies Research (2017) available at: https://doi.org/10.2139/ssrn.2922176; Mark Fenwick \& Erik P. M. Vermeulen, Technology \& Corporate Governance, The Texas Journal of Business Law (2019) vol. 48(1), 1-22. 